\title{
ENERGY AND MATERIAL SAVING TECHNOLOGIES IN SLOVENIAN MANUFACTURING FIRMS
}

\author{
Iztok Palcic \& Borut Buchmeister
}
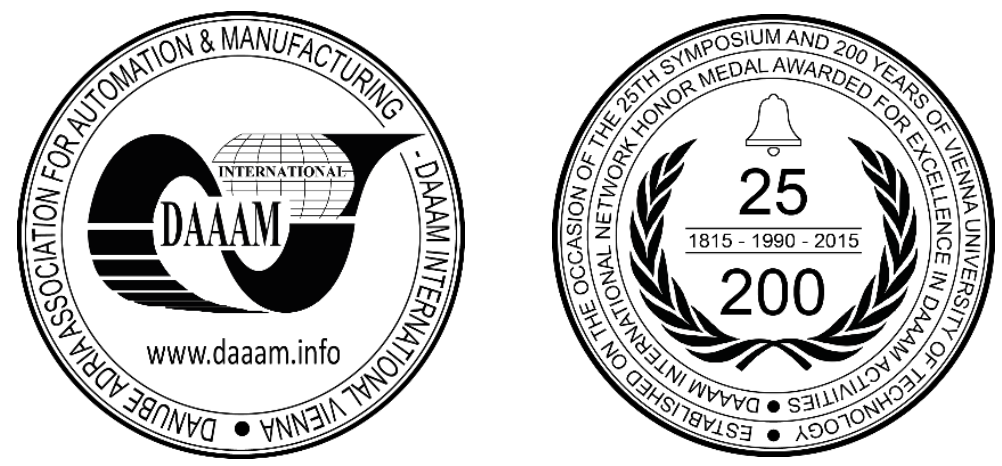

This Publication has to be referred as: Palcic, I[ztok] \& Buchmeister, B[orut] (2016). Energy and Material Saving Technologies in Slovenian Manufacturing Firms, Proceedings of the 27th DAAAM International Symposium, pp.00170022, B. Katalinic (Ed.), Published by DAAAM International, ISBN 978-3-902734-08-2, ISSN 1726-9679, Vienna, Austria

DOI: $10.2507 / 27$ th.daaam.proceedings.003

\begin{abstract}
The main objective of this paper is to map the adoption of technologies for energy reduction and resources consumption in production. The aim is also to contribute to the identification and understanding of the characteristics of the manufacturing firms that use this kind of energy and material saving technologies. Our research is based on the data from the largest European manufacturing survey and it includes data from Slovenia. The results show that the use of specific energy saving technologies and material saving technologies in Slovenian manufacturing firms is still modest. Dividing manufacturing firms based on technology intensity sectors and based on the relative energy efficiency we have concluded that firms in high technology industries focus less on energy efficiency than low technology firms. We also found out that firms with more implemented energy and material saving technologies are more likely to be more energy efficient.
\end{abstract}

Keywords: energy efficiency; manufacturing firm; survey; technology

\section{Introduction}

Manufacturing is defined as the transformation of materials and information into goods for the satisfaction of human needs. Turning raw materials into consumer products is also a major source of generating environmental pollution. Waste coming out from manufacturing activities is an environmental threat originating from several regions around the world [1]. Therefore, in recent years, mostly in response to increasing pressure from environmental regulations, many manufacturing firms have made significant efforts in cleaner production [2-3].

This paper is based on an empirical study that tries to contribute to world literature in the field of energy and material efficient technologies. The objective of this paper is firstly to map the adoption of the technologies for reduction of energy and resources consumption in production and, second to contribute to the identification and understanding of the characteristics of the manufacturing firms that use this kind of innovative technologies.

The paper is organized as follows. Introductory background and literature review about the energy efficiency in production is recalled. Next, we present our research methodology and methods used to analyse the characteristics of energy and material saving technologies' adoption and their adopters. Results and findings are presented for the manufacturing firms with the use of descriptive statistics. In the end we discuss our results and present some implications. 


\section{Literature review}

In recent years, firms have faced strong pressure from their stakeholders to implement environmental management, especially since the Rio Declaration in 1992 and the Kyoto Protocol in 1997 [4]. Manufacturing firms have been affected particularly strongly because through their production activities they are reputedly primary polluters [5]. Climate change, insecure energy supplies and rising energy prices are topics of increasing importance in today's society [6]. New energy efficient technologies can contribute to higher energy efficiency of enterprises, but there is a trade-off between a firm's environmental and economic performance [7].

Industrial energy efficiency plays a central role as the manufacturing industry accounts for about $75 \%$ of the world's yearly coal consumption, $44 \%$ of the world's natural gas consumption, and $20 \%$ of global oil consumption. In addition, these manufacturing firms also use $42 \%$ of all the electricity generated [8]. Although renewable energy technologies, such as photovoltaic technology, might be a long-term solution, more efficient energy use can make the highest and most economic contribution towards solving these problems in the short run. Using the available energy more efficiently is an effective countermeasure to rising energy needs and unsecure energy supplies [9, 10]. Bunse et al. [6] argue that examples in the literature and in the world of practice show that although the manufacturing sector has made continuous improvement in energy efficiency, economically beneficial energy efficiency potential is not yet exploited [6, 11].

Improving energy efficiency is regarded as one of the most important options to reduce the emissions of greenhouse gases and the dependency of countries on energy imports [12]. Measuring energy efficiency is the basis for controlling energy consumption in the production processes, for deciding about improvement measures and for tracking changes and improvements in energy efficiency [6]. Studies on energy consumption of manufacturing processes have provided fundamental information for improving energy efficiency and build a comprehensive foundation towards reducing the energy consumption of manufacturing processes [13]. There is also an on-going debate on the reasons why profitable investments to reduce energy consumption are not realized in firms $[14,15]$. There are several barriers to implementing energy efficiency improvement measures in firms, e. g.: payback periods, limited capital, a low priority given to energy efficiency by the management, lack of information, or "difficult-to-measure components" of energy investments [6, 16].

Bunse et al. [6] define energy efficiency as "the ratio of energy services out to energy input [meaning] getting the most out of every energy unit you buy". Increased energy efficiency may be accomplished by more efficient technology, energy recovery in the same process or further use of energy waste in different processes, increased energy conversion efficiency or optimized operational practices. Usually, energy efficiency indicators are ratios describing the relationship between an activity and the required energy. In the industrial sector, activities such as the production process of a product can be described in either economic or physical terms resulting in either economic or physical indicators. Economic indicators are useful at an aggregated level, such as for comparing different sectors; however, to gain insight into particular manufacturing processes, physical indicators are more suitable [17]. Examples of physical indicators are specific energy consumption [17-19], final energy efficiency improvement [20] etc. There is no single energy efficiency indicator that can be applied in every situation, but the appropriate indicators have to be defined depending on the decision to be made or decision tool to be applied [19].

Although there are many studies on energy efficiency analysing different aspects of the researched field, we have found no studies that analyse the use of specific energy and material saving technologies in manufacturing environment. Our study contributes to this area in a specific geographical area.

\section{Methodology}

We used data from European Manufacturing Survey (EMS) from 2009 for our research. The EMS is the largest European survey on manufacturing activities, coordinated by the Fraunhofer Institute for Systems and Innovation Research - ISI, Germany. The survey collects data on manufacturing strategies, the application of innovative organisational and technological concepts in production, personnel deployment and qualification, the production offshoring and back-sourcing activities, cooperation patterns etc. In addition, data on firm characteristics and performance indicators (R\&D expenses, productivity, returns on sales,) is collected. This paper uses data from Slovenian sub-sample, which had 64 responses. The survey was performed in manufacturing firms (NACE codes from 17 to 35) with at least 20 employees.

In recent years, only a few surveys have been launched in the world that analyse energy efficiency in manufacturing firms and their energy saving technologies (EST) and material saving technologies (MST) use. These existing surveys cover only some industrial sectors monitoring very specific technologies or cover only American and Asian countries. None of them include the European countries covered by EMS that also encompasses majority of manufacturing industries. Therefore, our survey added several questions relating environmental and energy issues. In that sense, EMS defines 10 general groups of technologies, 8 for energy efficiency and 2 for material consumption saving. These wide 
groups allow classifying any specific technology into one of them obtaining a global map of their use and level of implementation.

\section{EST included were:}

T1 control system for shut down of machines in off-peak periods;

$\mathrm{T} 2$ electric motors with rotation speed regulation;

T3 compressed air contracting;

T4 highly efficient pumps;

T5 low-temperature joining processes;

T6 retrieval of kinetic and process energy;

$\mathrm{T} 7$ combined cold, heat and power - Bi-/Tri-generation and

T8 waste material for in-house energy generation.

\section{We included two MST:}

T9 utilisation of recycled material in product manufacturing and T10 product recovery after product life cycle.

EST and MST are characterized in terms of use and also in terms of usage levels (extent of use) through a descriptive and a frequency analysis. Extent of actual use is referred to comparing the actual use of the technology in the firm to the most reasonable potential use. There are three levels: Extent of utilised potential "low" for an initial attempt to utilise, "medium" for partly utilized and "high" for extensive use.

We have analysed the characteristics of EST and MST adopters according to the OECD's taxonomy of manufacturing industries classified by their technological intensity [21]. We have formed two groups: "Low and Medium-Low technology" (LMT) with firms from NACE 17-19, 20-22, 23, 25, 26, 27, 28; and "Medium-High and High technology" (MHT) with firms from NACE 29, 30, 31, 32, 34 and 35. We created a discrete variable to group this classification into both categories: "Low and Medium-Low technology" - value 1, and "Medium-High and High technology" - value 2.

Next, we have classified technology adopters in three groups that represent the relative energy and materials consumption efficiency in production. These groups have been created from the responses of the question regarding the perception of their production efficiency in terms of actual material and energy consumption in comparison with other factories in their industry. Energy efficiency is therefore measured on a relative scale with values from 1 to 5 . The scale ranges from 1 meaning considerably much less efficient to value 5 considerably much more efficient. The value 2 indicates rather less efficient, 3 indicates equally efficient and 4 indicates rather more efficient. In the analyses, three groups have been created from this variable: "Less efficient" (including firms rated with values 1 or 2), "Equally efficient" (including firms rated with value 3 ) and "More efficient" (including firms rated with values 4 or 5).

\section{Results and findings}

Fig. 1 depicts the use of EST and MST for all manufacturing sectors presented. It is shown that "Speed control" is the most used technology with a 54\% of affirmative responses. The second position and quite far from the first one was EST "Control system for shut down of machines in off-peak periods" (37\%). The third and fourth technology in the use ranking were MST, namely "Recycled material in production" with a 34\%, and "Product recovery" with a $21 \%$. The high share of "Speed control" technology and its distance to other technologies could be misleading. The understanding of this technology could be misunderstood or widely interpreted. The term "Electric motors with rotation speed regulation" could be understood in the sense that almost each machine that produces any kind of motion or rotation with a common speed regulation system over the engine, have implemented this technology. For most machines this is not an option, but an intrinsic characteristic. A doubt arises to what extent "Speed control", presented as it is, should be considered an EST.

The graph in Fig. 2 presents a distribution of technologies used according their implementation degree and ranked by the highest implementation level to the lowest. This ranking compared to the simple use has changed. The "Speed regulation" technology was the most widely used technology, but only $22 \%$ of firms acknowledge high use of this technology - rank 7. This fact could be again related to the possible misunderstanding of the term "Speed regulation". Control system for shut down of machines in off-peak periods is highly used in just $16 \%$ of manufacturing firms that have this EST implemented. "Waste material for in-house energy generation" is the only EST highly used in at least 50\% of all implementations. "Compressed air contracting" and "Retrieval of kinetic and process energy" have no implementations with high use. Nevertheless, a reduction in the dispersion of the per cents of the highly implemented technologies is perceived compared with the per cents of the simple use of these technologies. This fact is more evident for EST, less for MST as both MST technologies are more widely used and both have relatively high extensive share of use. 
$\mathrm{T} 2$

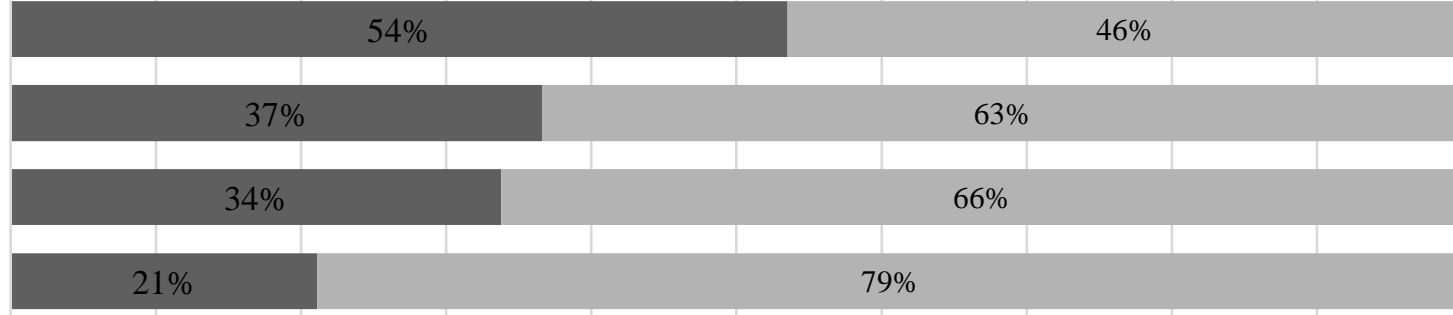

$\mathrm{T} 4$

$\mathrm{T} 3$

$\mathrm{T} 8$

T5

$\mathrm{T} 7$

T6

$0 \%$
$15 \%$
$85 \%$

$13 \%$

$87 \%$

$10 \%$

$90 \%$

$7 \%$

$6 \%$

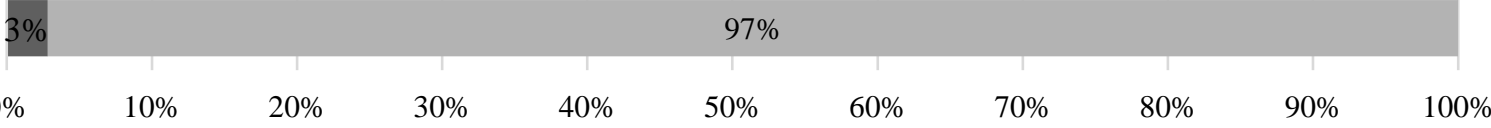

-Use $\square$ No use

Fig. 1. Use of EST and MST for all manufacturing sectors

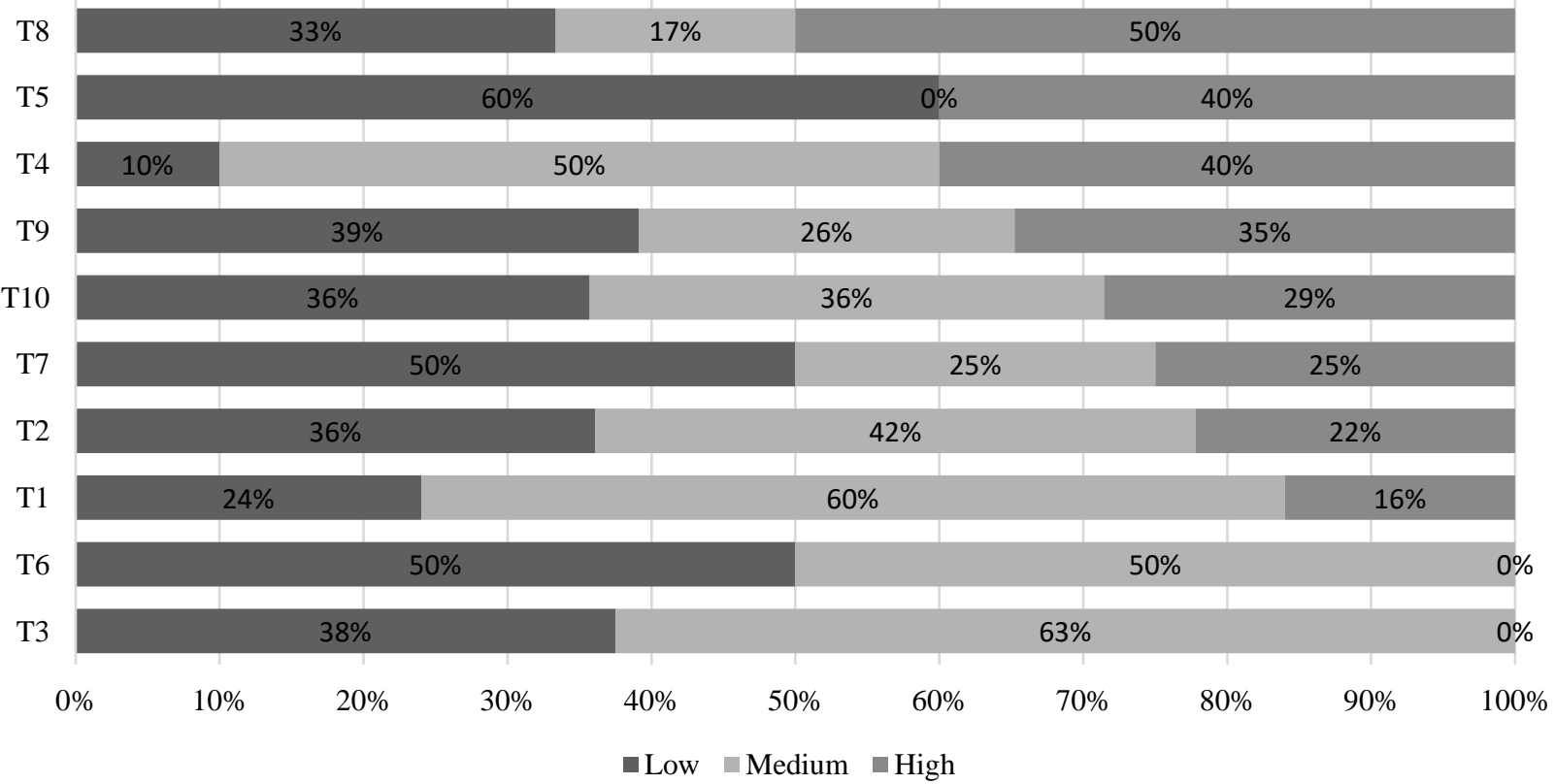

Fig. 2. Implementation degree of EST and MST for all manufacturing sectors

Fig. 3 presents EST and MST in accordance to three technological intensity groups. The technologies are ranked based on the share of use in "Medium-High and High technology" group (from the highest to the lowest share). "Compressed air contracting" is the technology with the highest per cent of use in "Medium-High and High technology" group with $78 \%$, followed by "Low-temperature joining processes" with $60 \%$. "Highly efficient pumps ", "Speed regulation" and "Bi-/Tri-generation" are the other three EST used in at least 50\% of firms within "Medium-High and High technology" group. "Control system for shut down of machines in off-peak periods" technology is used in slightly less than $50 \%$ of "Medium-High and High technology" group. Both MST technologies are more often used in "Low and Low-Medium technology" group (around 60\%). "Retrieval of kinetic and process energy" is never used in "Medium-High and High technology" group. "Waste material for in-house energy generation" is also predominately used in "Low and LowMedium technology" group. 


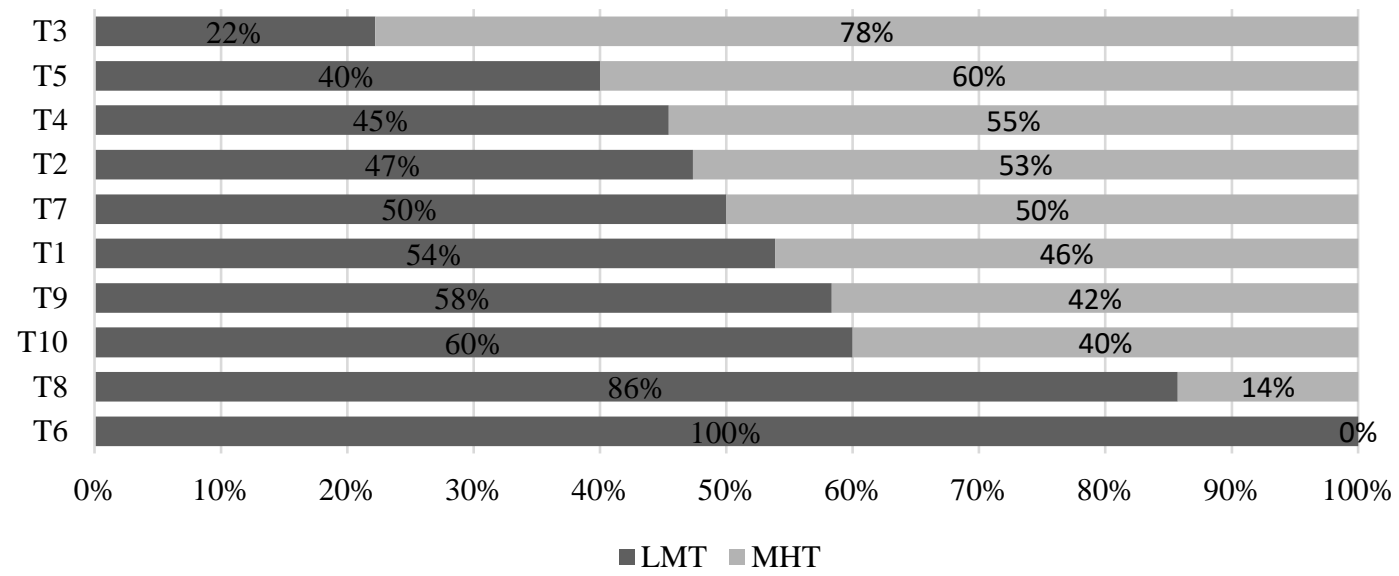

Fig. 3. Implementation per cent of EST and MST by technological sector

Fig. 4 presents EST and MST in accordance to three groups that represent the relative energy and materials consumption efficiency in production. The technologies are ranked based on the share of use in the "More effective" group (from the highest to the lowest share). In general, the most predominant group is "More effective" group, since 8 of 10 technologies are implemented in most of the firms from this group. Only "Highly efficient pumps" and "Compressed air contracting" are most often used in "Equally efficient" group. "Low-temperature joining processes" is the technology with the highest share of "More efficient" group with a $80 \%$, followed by "Product recovery" and "Waste material for inhouse energy generation" technologies. It is very obvious that EST and MST are hardly used in "Less efficient" group with very low shares of use. The only exception is "Bi-/Tri-generation" technology, but its implementation in general is very low. 5 out of 10 EST and MST are not implemented in any of "Less efficient" group.

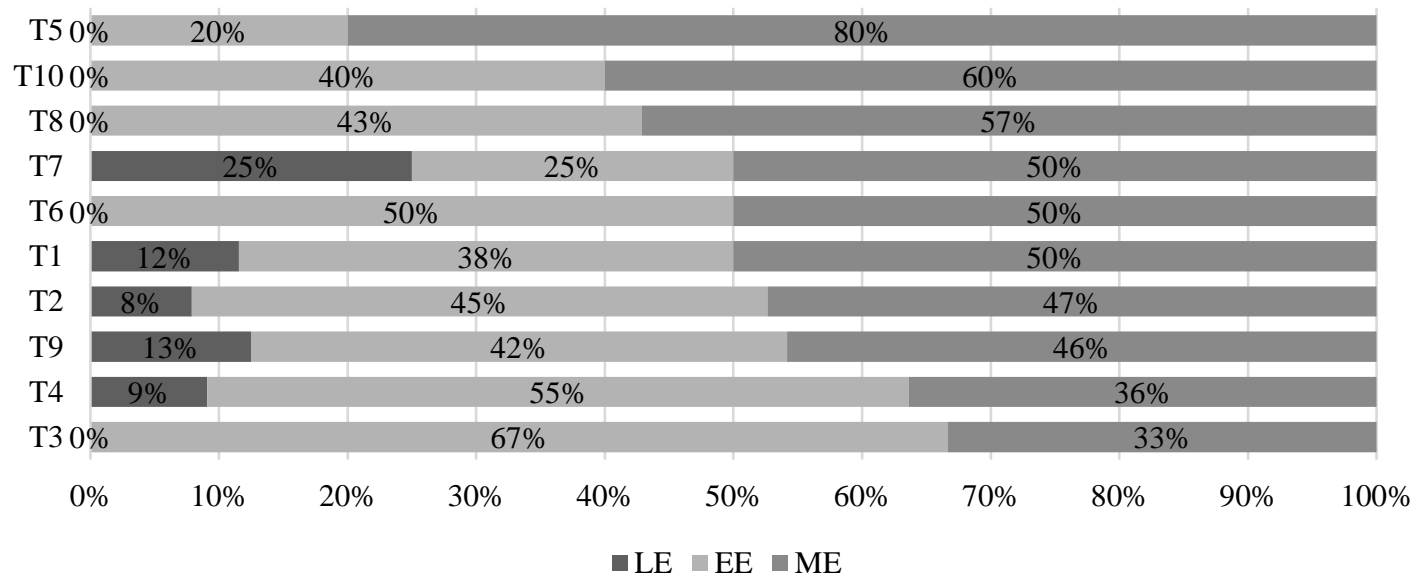

Fig. 4. Implementation per cent of EST and MST by level of efficiency relative to the sector

\section{Discussion}

Based on our analysis several conclusions can be drawn. General observation on the use of EST and MST is that the use of these technologies in manufacturing firms is still relatively low (from $3 \%$ to $37 \%$ ). The only exception is "Speed control" technology with 54\%. The first conclusion is the fact that analysing energy efficiency groups we have observed that there is a slight decrease of the technological intensity values from "Less efficient" group to "More efficient" group. The average technological intensity in "Less efficient" group was 1,71, in "Equally efficient" group 1,44 and "More efficient" group 1,40. On the other hand, "Low and Low-Medium technology" group has a slightly higher average of material and energy efficiency in production than "Medium-High and High technology" group (3,39 vs. 3,13). Both these facts could reveal a possible negative relationship between energy efficiency in production and technological intensity of firms, at least on average. This could lead to a conclusion that firms in high technology industries focus less on energy efficiency than low technology firms. Secondly, both MST are ranked third and fourth in general use. But it is interesting to see that they are mostly used in low and medium technology sector, not in high technology one. Thirdly, only $10 \%$ of all manufacturing firms claims to be less energy efficient than firms from their sector, 35\% believes they are more energy efficient than others. We calculated that MST and EST are used on average in $50 \%$ of firms within "More efficient" group, $43 \%$ within "Equally efficient" group and $7 \%$ within "Less efficient" group. Based on this fact we could assume that manufacturing firms are more efficient if they use at least one EST or MST. 
Our research has several limitations. The first is that only descriptive statistics was used to map the characteristics of energy efficient technologies and their adopters. To draw further conclusions in the future several advanced statistical methods will be used (e. g. linear regression for quantitative independent variables and ordinal logistic regression). We will further explore the relationship between the implementation of energy efficient technologies and environmental performance of manufacturing firms. Our limitation is also the narrow geographical coverage and the fact that no similar previous data exists to compare our findings. We will expand our research with data from other countries from EMS consortium. Despite these shortcomings, our contribution explains the use of energy and material efficient technologies, the characteristics of their adopters and indicates a possible influence of these technologies on environmental performance of the manufacturing firms, thus giving some business implications to managers to decide to invest in these technologies.

\section{References}

[1] Marland, G., Boden, T. A. \& Andres, R. J. (2007). Global, Regional, and National CO2 Emissions, In: Trends: A Compendium of Data on Global Change, Carbon Dioxide Information Analysis Center, Oak Ridge National Laboratory, US Department of Energy, Oak Ridge, Tenn., USA

[2] Tseng, M. L., Lin, Y. H. \& Chiu, A. S. F. (2009). Fuzzy AHP-based study of cleaner production implementation in Taiwan PWB manufacturer, Journal of Cleaner Production, Vol. 17, No. 14, pp. 1249-1256

[3] Kliopova, I. \& Staniskis, J. K. (2006). The evaluation of cleaner production performance in Lithuanian industries, Journal of Cleaner Production, Vol. 14, pp. 1561-1575

[4] Nishitani, K., Kaneko, S., Hidemichi, F. \& Komatsu, S. (2011). Effects of the reduction of pollution emissions on the economic performance of firms: an empirical analysis focusing on demand and productivity, Journal of Cleaner Production, Vol. 19, pp. 1956-1964

[5] Dessus, S. \& Bussolo, M. (1998). Is there a trade-off between trade liberalization and pollution abatement?, Journal of Policy Modeling, Vol. 20, pp. 11-31

[6] Bunse, K., Vodicka, M., Schönsleben, P., Brülhart, M. \& Ernst, F. O. (2011). Integrating energy efficiency performance in production management - gap analysis between industrial needs and scientific literature, Journal of Cleaner Production, Vol. 19, pp. 667-679

[7] Micieta, B., Zavodska, L., Rakyta, M. \& Binasova, M. (2015). Sustainable concept for green logistics and energy efficiency in manufacturing, In: DAAAM Scientific Book 2015, B. Katalinic (Ed.), pp.391-400, DAAAM International, ISBN 978-3-902734-05-1, Vienna, Austria

[8] Thollander, P., Danestig, M. \& Rohdin, P. (2007). Energy policies for increased industrial energy efficiency: Evaluation of a local energy programme for manufacturing SMEs, Energy Policy, Vol. 35, pp. 5774-5783

[9] Tanaka, K. (2008). Assessment of energy efficiency performance measures in industry and their application for policy, Energy Policy, Vol. 36, pp. 2887-2902

[10] International Energy Agency. (2008). Assessing Measures of Energy Efficiency Performance and Their Application in Industry. Available from: http://www.iea.org/papers/2008/JPRG_Info_Paper.pdf Accessed: 201607-01

[11] International Energy Agency. (2009). Implementing Energy Efficiency Policies 2009. Are IEA Member Countries on Track? Available from: http://www.gbv.de/dms/zbw/613955536.pdf Accessed: 2016-07-01

[12] Neelis, M., Ramirez-Ramirez, A., Patel, M., Farla, J., Boonekamp, P. \& Blok, K. (2007). Energy efficiency developments in the Dutch energy-intensive manufacturing industry, 1980-2003, Energy Policy, Vol. 35, pp. 6112-6131

[13] Li, W., Winter, M., Kara, S. \& Herrmann, C. (2012). Eco-efficiency of manufacturing processes: A grinding case. CIRP Annals - Manufacturing Technology, Vol. 61, pp. 59-62

[14] De Groot, H. L. F., Verhoef, E. T. \& Nijkamp, P. (2001). Energy saving by firms: decision making, barriers and policies, Energy Economics, Vol. 23, pp. 717-740

[15] Paton, B. (2001). Efficiency gains within firms under voluntary environmental initiatives, Journal of Cleaner Production, Vol. 9, pp. 167-178

[16] Sardianou, E. (2008). Barriers to industrial energy efficiency investments in Greece, Journal of Cleaner Production, Vol. 16, pp. 1416-1423

[17] Phylipsen, D., Blok, K., Worrell, E. \& de Beer, J. (2002). Benchmarking the energy efficiency of Dutch industry: an assessment of the expected effect on energy consumption and CO2 emissions, Energy Policy, Vol. 30, pp. 663-679

[18] Farla, J., Blok, K. \& Schipper, L. (1997). Energy efficiency developments in the pulp and paper industry: a cross-country comparison using physical production data, Energy Policy, Vol. 25, pp. 745-758

[19] International Energy Agency. (2007). Tracking Industrial, Energy Efficiency and CO2 Emissions. Available from: http://www.iea.org/textbase/nppdf/free/2007/tracking_emissions.pdf Accessed: 2016-07-01

[20] Irrek, W. \& Thomas, S. (2006). Der Energie Spar Fonds für Deutschland (Energy Saving Funds for Germany), Hans-Böckler-Stiftung, Düsseldorf, Germany

[21] OECD. (2005) Directorate for Science, Technology and Industry, stan indicators (2005 edition): 1980-2003. Organisation for Economic Co-operation and Development, Paris, France. Available from: http://www.oecd.org/industry/industryandglobalisation/40230754.pdf Accessed: 2016-07-01. 